\title{
Airborne transmission of coronavirus disease 2019: a clinician's perspective
}

Myoung-don $\mathrm{Oh}$

Department of Internal Medicine, Seoul National University College of Medicine, Seoul, Korea

Received: July 3, 2020

Accepted: August 24, 2020

\section{Correspondence to}

Myoung-don Oh, M.D.

Department of Internal

Medicine, Seoul National

University College of Medicine, 101 Daehak-ro, Jongno-gu,

Seoul 03080, Korea

Tel: +82-2-2072-2945

Fax: +82-2-762-9662

E-mail:mdohmd@snu.ac.kr

https://orcid.org/0000-0002-

2344-7695
Since the outbreak of coronavirus disease 2019 (COVID-19), scientists have been debating whether severe acute respiratory syndrome coronavirus 2 (SARS-CoV-2) spread by airborne or droplet. Those supporting airborne transmission claim it based on the size, travel distance, floating time of the respiratory particles, and detection of the virus in the aerosols. The scientists in the other camp do not agree, highlighting (1) the experimental conditions for the aerosol physics, air flow dynamics, and the virus survival studies do not reflect normal human cough conditions; (2) the infectious dose of SARS-CoV-2 is not known yet; (3) droplet and fomite transmission could also explain the human-to-human transmissions [1]. Most of the discussions have been focused on either the generation of respiratory particles (source) or survival and transportation of the virus (environment); discussions on its passage from the portal of entry to the multiplication sites (host) are largely missing.

Once the droplets landed on the eye, nose, or mouth, the body fluids of tear, nasal mucus, or saliva move the virus to the replication sites. The nose is not a good portal of entry, as the virus that landed near the nostril would not get into the nasal mucosa, because the lining cells of the vestibule are squamous epithelial cells, which do not support movement or proliferation of the vi- rus. The virus that landed on the lips or oral cavity may get into the saliva of the mouth, and move to the multiplication sites on the oropharynx (Fig. 1A). The virus that landed on the eye can descend the inferior meatus of the nose through the nasolacrimal duct. Therefore, of the three portals of entry for the virus in the respiratory droplets, only the eye may provide a passage to the nasal cavity.

Olfactory dysfunction of COVID-19 is a common symptom of COVID-19. If it were due to droplet transmission, the virus that arrived at the inferior meatus through the nasolacrimal duct should move to the olfactory mucosa, which is located on the apex of the nasal cavity, especially in the region of the superior turbinate (Fig. 1B). As the mucociliary clearance mechanism would move the nasal mucus backward to the nasopharynx, it is hardly conceivable that the virus could move upward to reach the olfactory region. Contiguous extension of infection by cell-to-cell spread of the virus might be a possibility. If that were the case, the upper respiratory symptoms may develop earlier than, and as commonly as olfactory dysfunction. But, in many patients, olfactory dysfunction is the only or earliest symptom. Indeed, olfactory dysfunction is relatively common (up to $98 \%$ ) [2,3], whereas upper respiratory symptoms, such as rhinorrhea and 
A
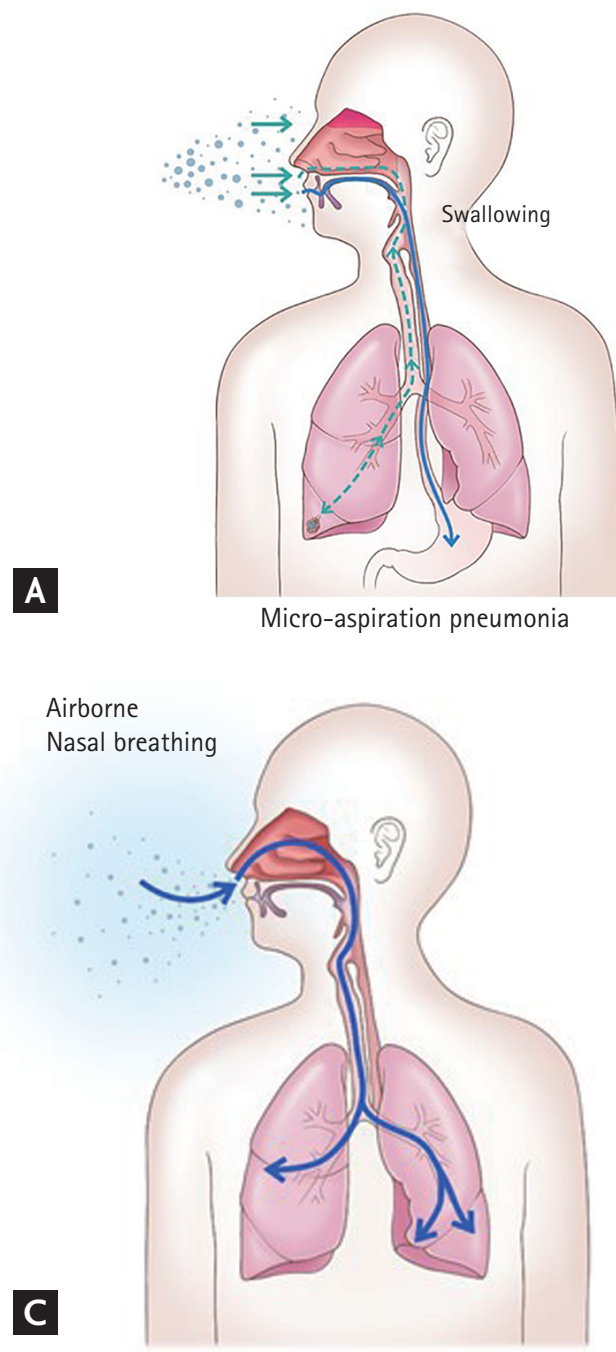

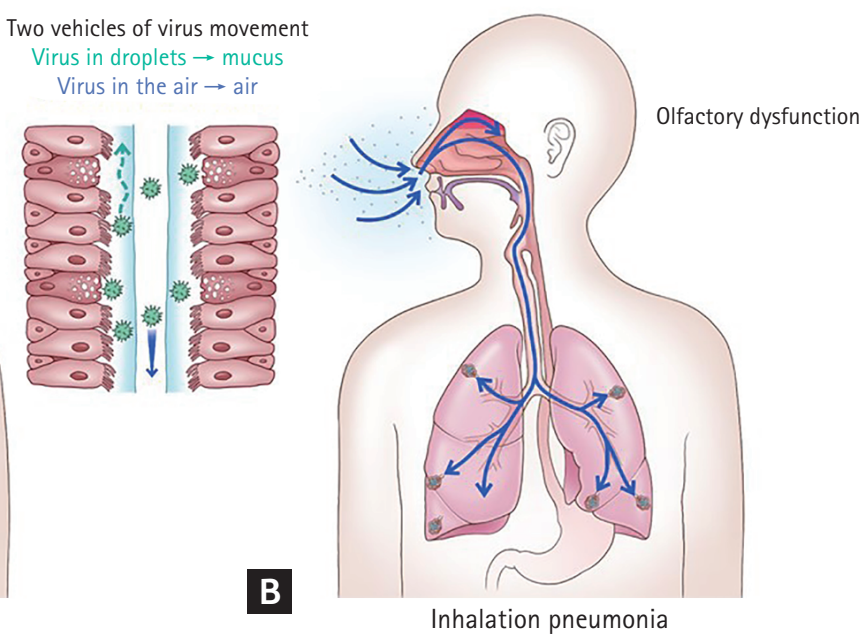

Airborne

Mouth breathing (e.g., talking, singing, exercise)

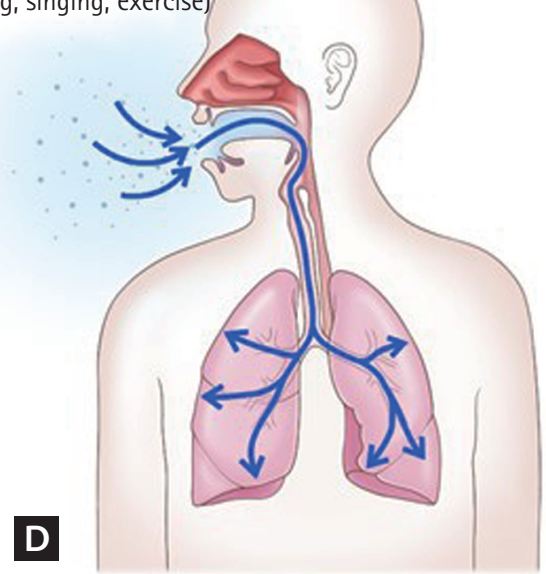

Figure 1. Two vehicles of pathogen movement in host: body fluids for droplets (A) and air for aerosols (B). The pathogen in droplets or on contaminated hands land on the eye, nose, or mouth (A), and tear, nasal mucus, or saliva moves it to the replication sites on the upper respiratory tract, respectively. It is normally swallowed to the gastrointestinal tract. The pathogen may get into the lower respiratory tract, but mucociliary clearance mechanism removes it in healthy hosts. In hosts with impaired mucociliary function, micro-aspiration pneumonia may occur. The pathogen in aerosols (B) may penetrate directly into the lower respiratory tract and alveoli, causing inhalation pneumonia. It may also reach the olfactory mucosa in the nasal cavity, causing olfactory dysfunction. Mouth breathing may cause more severe pneumonia than nasal breathing. Compared to nasal breathing (C), mouth breathing (D) is more vulnerable to inhalation pneumonia, because of a larger portal of entry, faster air flow, and bypassing the host defense mechanisms in the nasal cavity. During nasal breathing, the host defense mechanisms in the nasal cavity may reduce the amount of the invading pathogens. During mouth breathing, a larger amount of the pathogens may penetrate into the lungs, causing more severe pneumonia.

sore throat are uncommon $(<15 \%)[4,5]$. Considering the anatomy and physiology of the upper respiratory tract, airborne transmission is more plausible mode of infection for olfactory dysfunction of COVID-19 than droplet transmission.
COVID-19 pneumonia may also provide important clues to the mode of transmission. If it were due to droplet transmission, the virus that landed on the upper respiratory tract through the portals of entry should descend into the lower respiratory tract. As the 
Table 1. Droplet vs. airborne transmission

\begin{tabular}{lll}
\hline & \multicolumn{1}{c}{ Droplet infection } & Airborne infection \\
\hline $\begin{array}{l}\text { Portal of entry } \\
\text { Vehicles for virus movement in host }\end{array}$ & $\begin{array}{l}\text { Eye, nostril, mouth } \\
\text { Body fluids (tear, nasal mucus, } \\
\text { saliva } \rightarrow \text { respiratory mucus) }\end{array}$ & Air \\
Initial sites of virus proliferation & Nasal or oral cavity & Upper and lower respiratory \\
& Trigger & Mact or lung
\end{tabular}

mucociliary mechanism would clear it in healthy hosts, COVID-19 pneumonia would develop mostly in hosts with impaired mucociliary function, as an aspiration pneumonia. However, the following clinical characteristics of COVID-19 pneumonia suggest inhalation rather than aspiration pneumonia: (1) it may occur in healthy young adults without risk factors for aspiration; (2) upper respiratory symptoms are uncommon, suggesting the virus directly penetrates into the lungs, bypassing the upper airway; and (3) the typical distribution pattern of pneumonic lesions of COVID-19, i.e., bilateral, multiple, upper and middle lobes involvement, and peripheral location (Table 1) [6].

Some experts raise questions about the possibility of airborne transmission in the community, indicating that basic reproduction number $\left(\mathrm{R}_{\mathrm{o}}\right)$ of 2.5 to 3.0 for COVID-19 is much lower than that for the well-known airborne infections, such as measles $\left(\mathrm{R}_{\mathrm{o}}>12\right)$ [7]. Howev$\mathrm{er}$, in an infectious disease that requires a large amount of virus to cause infection (i.e., high infectious dose), only those who are heavily exposed at a near distance from the source (short-range airborne infection) may develop symptoms; it would be difficult to prove a longrange airborne infection, especially when asymptomatic or subclinical infection are frequent [8]. Indeed, it took years of painstaking experiments to prove airborne transmission of tuberculosis, an obligatory airborne infection with $\mathrm{R}_{\mathrm{o}}$ of 0.24 to 4.3 [9]. Therefore, a low $\mathrm{R}_{\mathrm{o}}$ does not necessarily exclude the possibility of airborne transmission. The author believe that short-range airborne transmission of SARS-CoV-2 may occur in the community.

What would drives the airborne transmission in the community? Based on the following reasons, the author also believe that talking is the major driver of SARSCoV-2 transmission: (1) it generates airborne particles; (2) talking is more frequent than coughing and sneezing, even in COVID-19 patients; (3) during talking, we face each other, at a short distance- a condition that facilitates transmission of respiratory pathogens. And more importantly, during talking; (4) we breathe in through the mouth. Compared to nasal inhalation, mouth inhalation is more vulnerable to inhalation pneumonia, because the portal of entry is larger, the airflow is faster, and aerosols can penetrate directly into the lungs, bypassing the innate host defense mechanisms in the nasal cavity (Fig. 1 C and $1 D$ ).

What measures should we take to prevent transmission of SARS-CoV-2 in the community? Physical distancing, wearing face masks, and frequent ventilation 
may reduce the risk of the airborne transmission. In addition, refraining from talking would further reduce the risk of inhalation of, as well as generation of, aerosols containing SARS-CoV-2. In Korea, we have been advocating for "refrain from talking" in closed indoors, elevators, and on public transportation.

The distribution of expiratory particles size is a spectrum, not a dichotomy of droplets vs aerosols. Within a short distance from the source, host may receive droplet spray and aerosol shower simultaneously. Clinical characteristics of olfactory dysfunction and pneumonia in COVID-19 patients suggest that short-range airborne transmission of SARS-CoV-2 commonly occurs in the community. The traditional paradigm of droplet versus aerosol dichotomy needs to be revised.

\section{Conflict of interest}

No potential conflict of interest relevant to this article was reported.

\section{REFERENCES}

1. World Health Organization. Transmission of SARSCoV-2: implications for infection prevention precautions [Internet]. Geneva (CH): WHO, 2020 [cited 2020 Sep 7]. Available from: https://www.who.int/news-room/commentaries/detail/transmission-of-sars-cov-2-implications-for-infection-prevention-precautions.

2. Chung TW, Sridhar S, Zhang AJ, et al. Olfactory dysfunc- tion in coronavirus disease 2019 patients: observational cohort study and systematic review. Open Forum Infect Dis 2020;7:ofaa199.

3. Speth MM, Singer-Cornelius T, Oberle M, Gengler I, Brockmeier SJ, Sedaghat AR. Olfactory dysfunction and sinonasal symptomatology in COVID-19: prevalence, severity, timing, and associated characteristics. Otolaryngol Head Neck Surg 2020;163:114-120.

4. Guan WJ, Ni ZY, Hu Y, et al. Clinical characteristics of coronavirus disease 2019 in China. N Engl J Med 2020;382:1708-1720.

5. Argenziano MG, Bruce SL, Slater CL, et al. Characterization and clinical course of 1000 patients with coronavirus disease 2019 in New York: retrospective case series. BMJ 2020;369:m1996.

6. Altmayer S, Zanon M, Pacini GS, et al. Comparison of the computed tomography findings in COVID-19 and other viral pneumonia in immunocompetent adults: a systematic review and meta-analysis. Eur Radiol 2020;30:64856496.

7. Klompas M, Baker MA, Rhee C. Airborne transmission of SARS-CoV-2: theoretical considerations and available evidence. JAMA 2020;324:441-442.

8. Roy CJ, Milton DK. Airborne transmission of communicable infection: the elusive pathway. N Engl J Med 2004;350:1710-1712.

9. Ma Y, Horsburgh CR, White LF, Jenkins HE. Quantifying TB transmission: a systematic review of reproduction number and serial interval estimates for tuberculosis. Epidemiol Infect 2018;146:1478-1494. 